\title{
Interspecific variations in responses of Festuca rubra and Trifolium pratense to a severe clipping under environmental changes
}

\author{
Junyan Zhang ${ }^{1,3,5}$, Genwei Cheng ${ }^{1}$, Feihai Yu ${ }^{2,4}$, Norbert KräUCHI ${ }^{2}$ \& Mai-He Li ${ }^{1,2 *}$ \\ ${ }^{1}$ Institute of Mountain Hazards and Environment, Chinese Academy of Sciences, Chengdu 610041, China \\ ${ }^{2}$ Swiss Federal Research Institute WSL, Zuercherstrasse 111, CH-8903 Birmensdorf, Switzerland; e-mail: Maihe.li@wsl.ch \\ ${ }^{3}$ Department of Biology, Acadia University, Wolfville, NS, B4P 2R6, Canada \\ ${ }^{4}$ Institute of Botany, Chinese Academy of Sciences, Beijing 100093, China \\ ${ }^{5}$ Graduate University of Chinese Academy of Sciences, Beijing 100049, China
}

\begin{abstract}
Understanding and predicting possible responses of grassland species to global change is of important meaning for adapting grassland management to a changed and changing environment. A laboratory clipping experiment was conducted to examine the interspecific responses in an ecological context of competition and environmental changes. Festuca rubra and Trifolium pratense, either in monoculture or two- and three-species mixtures, were grown in three environmental combinations (ambient and increased temperature, repetitive $\mathrm{N}$ supply, and simulated acid rain), respectively. After a growth time of three months, plants were clipped at the height of $1.0 \mathrm{~cm}$ above soil surface. Plant height and aboveground biomass prior clipping, and survival rate and regrowth (height and biomass) after clipping were analyzed. F. rubra and T. pratense responded differently in compensatory growth and competition intensity to environmental change and co-existing species. The differences in their physiological and ecological traits may account for species-dependent responses. The present study emphasizes that predicting the plant assemblage response in the face of global change requires in understanding the integrating effects of abiotic and biotic factors.
\end{abstract}

Key words: climate change; compensatory growth; defoliation; grassland ecosystem; interspecific competition; speciesspecific response

Abbreviations: MonoF/MonoT, Monoculture of Festuca rubra or Trifolium pratense; MixFT, Mixed culture of F. rubra and T. pratense; MixFTO, Mixed culture of F. rubra, T. pratense, and Oenothera biennis; MixFTH, Mixed culture of F. rubra, T. pratense and Hieracium pilosella; $\mathrm{T}_{0} \mathrm{~N}_{0} \mathrm{~W}_{6.0}$, ambient temperature + no additional $\mathrm{N}$ applied + watering at $\mathrm{pH} 6.0$; $\mathrm{T}_{+} \mathrm{N}_{+} \mathrm{W}_{6.0}$, increased temperature $+\mathrm{N}$-addition + watering at $\mathrm{pH} 6.0 ; \mathrm{T}_{+} \mathrm{N}_{+} \mathrm{W}_{4.0}$, increased temperature $+\mathrm{N}$-addition + watering at $\mathrm{pH} 4.0$.

\section{Introduction}

Grazing/mowing is a major impact factor on plant persistence and grassland ecosystems (McNaughton 1983; Belsky 1986). Selective defoliation by grazing/mowing not only affects the growth and survival of individual plants, also modifies species composition and species interactions (Crawley 1997; Augustine \& McNaughton 1998). A single severe defoliation can lead to an immediate decrease in photosynthesis (Parsons et al. 1983) and $\mathrm{N}$ uptake (Lestienne et al. 2006), resulting in reductions in root carbohydrate reserves (Gonzalez et al. 1989; Morvan-Bertrand et al. 1999), and even to root and tiller senescence (Jarvis \& Macduff 1989). However, defoliation does not always impose deleterious effects. Many plants possess substantial compensatory mechanisms following defoliation damage, through increasing relative growth rate (Staalduinen \& Anten 2005), intensifying nutrient uptake capacity (Chapin \&
McNaughton 1989), or stimulating photosynthesis rate (Painter \& Detling 1981).

The regrowth potential following defoliation may be affected by the presence or absence of co-existing species (Lee \& Bazzaz 1980). In the literature, two mechanisms of interspecific competition in influencing plant regrowth are extensively discussed. The first, and most studied, focuses on the shading effects of taller neighbouring species. By removal of the canopy, it may therefore moderate competition by increasing light to small co-occurring species (McNaughton 1992). The second mechanism is related to the neighbour identity, which associated with species-specific ability to acquire resources (Hartley \& Amos 1999) and to suppress the potential competitors (Louda et al. 1990; Bullock et al. 2001). Species which are more able to regrow, or regrow more rapidly after defoliation, are able to dominate after grazing (Augustine \& McNaughton 1998; Bullock et al. 2001).

\footnotetext{
* Corresponding author
} 
Today's plant communities are the result of longterm adaptation to their site factors, including climatic and anthropogenic impacts. Changed and changing environment conditions will lead to changes in availability of resources (nutrients, light and water) and interactions between co-existing species (Hilbert et al. 1981; Li et al. 2006). The rapid environmental changes that humans are currently causing in the natural world will certainly play both direct and indirect roles in plant response to defoliation. Over the past 100 years, the earth is rising by $0.74 \pm 0.18^{\circ} \mathrm{C}$ in mean surface temperatures (IPCC 2007). Deposition of human-derived soluble nitrogen has reached unprecedented levels, and now exceeds natural nitro-fixation by the globe's biota (Vitousek et al. 1997). Nitrogen deposition increases N mineralisation, but it may also accelerate soil acidification by increased ammonium oxidation (Vitousek et al. 1997). Simultaneously, increased atmospheric carbon dioxide and sulphuric compound contribute to an additional acid deposition regionally, causing changes in species compositions (Houdijk et al. 1993; Roem \& Berendse 2000). Understanding and predicting possible responses of grassland species to global change is of important meaning for adapting grassland management to a changed and changing environment.

Many studies have investigated the responses of a single plant species (without co-existing species) to just one factor (e.g. $\mathrm{CO}_{2}$, elevated temperature, Ndeposition) contributing to major global changes (Shaw et al. 2002). The combined effects of co-occurring environmental changes on plant communities or ecosystems are, however, still poorly understood (Zavaleta et al. 2003). The effects of multiple environmental changes may be synergistic or antagonistic (Sala et al. 2000). To understand the combined effects of multiple environmental changes and defoliation on grassland ecosystem, we, therefore, grown Festuca rubra L. and Trifolium pratense L., either in monoculture, or in twoand three-species mixtures with Oenothera biennis S. and Hieracium pilosella L., under different combinations of environmental factors (increased air temperature, nitrogen supply, and simulated acid rain). We addressed following questions: i) Species-specific regrowth response to interaction between competition and abiotic conditions following clipping; ii) Clipping effects on competition intensity for both species; iii) Plant traits determining potential species-dependent compensatory growth.

\section{Material and methods}

\section{Plant materials}

The target species were F. rubra, and T. pratense, two of the most important components of meadows and pastures in Central Europe. The selected co-existing species were $O . b i$ ennis and $H$. pilosella. Seeds of the four experimental species were obtained from the company of Fanoca Saemereienzentrum (Winterthur, Switzerland). Seeds were sown on May 24, 2004. Seedlings were transplanted at the 2-leaf stage, when $O$. biennis was $\sim 2 \mathrm{~cm}$ and the others were $\sim 6 \mathrm{~cm}$ in height, into plastic pots $(14 \mathrm{~cm}$ in diameter and $14 \mathrm{~cm}$ in

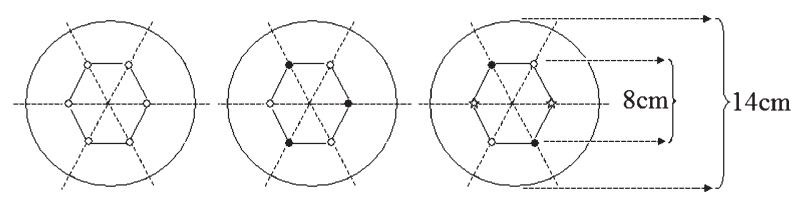

(a)

(b)

(c)

Fig. 1. Experimental layout: a - Monoculture of 6 Festuca rubra or 6 Trifolium pratense plants (MonoF/MonoT); b - Mixtures of $3 \mathrm{~F}$. rubra and $3 \mathrm{~T}$. pratense plants (MixFT); and c - Mixtures of $2 \mathrm{~F}$. rubra +2 T. pratense +2 Oenothera biennis plants and/or $2 \mathrm{~F}$. rubra +2 T. pratense +2 Hieracium pilosella plants (MixFTO/MixFTH).

height) on June 11, 2004. The potting soil was a 1:1 (v/v) mixture of sand and peat. Each pot contained 1700 g potting soil $(\mathrm{pH} \sim 5)$ with $3.06 \mathrm{~g}$ slow-release fertilizer $(15 \% \mathrm{~N}$, $9 \% \mathrm{P}_{2} \mathrm{O}_{5}, 9 \% \mathrm{~K}_{2} \mathrm{O}$ and $\left.3 \% \mathrm{MgO}\right)$. Six seedlings were arranged and planted per pot in monocultures and mixtures (Fig. 1). There were totally five culture treatments.

Each culture treatment was subjected to one of three environmental treatments: i) ambient temperature, basal $\mathrm{N}$ supply and watering with water at pH6.0 $\left(\mathrm{T}_{0} \mathrm{~N}_{0} \mathrm{~W}_{6.0}\right)$; ii) increased temperature, $\mathrm{N}$-addition, and watering with water at pH6.0 $\left(\mathrm{T}_{+} \mathrm{N}_{+} \mathrm{W}_{6.0}\right)$; and iii) increased temperature, $\mathrm{N}$-addition, and watering with simulated acid rain at pH4.0 $\left(\mathrm{T}_{+} \mathrm{N}_{+} \mathrm{W}_{4.0}\right)$. Each culture treatment was repeated six times $(n=6)$.

\section{Environmental treatments}

The experiment was conducted at Swiss Federal Institute for Forest, Snow and Landscape Research (WSL). Two controlled environment glasshouse compartments were used to impose the temperature treatments. The average temperature achieved by air warming $\left(\mathrm{T}_{+}\right)$were $24.7 \pm 0.9^{\circ} \mathrm{C}$ in daytime and $19.0 \pm 1.2^{\circ} \mathrm{C}$ at night, while for ambient treatment $\left(\mathrm{T}_{0}\right)$, the temperature was averaged $22.7 \pm 0.8^{\circ} \mathrm{C}$ during the day and $18.4 \pm 1.4^{\circ} \mathrm{C}$ at night, i.e. warming treatment increased air temperature by $\sim 1.7-2.1^{\circ} \mathrm{C}$ in daytime and $\sim 0.3-0.9^{\circ} \mathrm{C}$ at night. Plants were watered using $10 \mathrm{~L}$ water for 30 pots on a weekly basis. Pots in $\mathrm{W}_{6.0}$ treatments received water ( $\mathrm{pH}$ 6.0) weekly, while pots in $\mathrm{W}_{4.0}$ treatment were watered once a week alternately using water ( $\mathrm{pH}$ 6.0) and simulated acid rain ( $\mathrm{pH} 4.0)$. For plants treated with $\mathrm{N}$-addition $\left(\mathrm{N}_{+}\right)$, the additional $\mathrm{N}$ (Harnstoff, $46 \% \mathrm{~N}$; Lonza, Valais, Switzerland) was applied in combination with watering (10 g Harnstoff dissolved in $10 \mathrm{~L}$ water) every other week, from July 12 to October 29 on a total of 8 occasions. All pots were randomly placed in the glasshouse and then randomly moved to different positions every week during the experimental period to avoid edge effects on plant growth.

On September 6, 2004, after recording individual height, plants were clipped to $1.0 \mathrm{~cm}$ above the soil surface. The clippings were collected and sorted into each species for determining pre-clipping aboveground biomass. After 3month's regrowth, plants were harvested on December 4, 2004. The number of individual plants surviving and regrowth heights were recorded. Pots were then immersed in water and roots, washed free from soil. Plants were sorted into species where the cultures were mixed. Plant biomass was separated into above- and belowground parts, and weighed to nearest $0.001 \mathrm{~g}$ after oven-drying at $70^{\circ} \mathrm{C}$ for 72 hours. 


\section{Data analysis}

The survival rate for both $F$. rubra and T. pratense at the end of the experiment was averaged by each of the replications. Data were ranked transformed before running a standard two-way ANOVA (Conover \& Iman 1981), using environmental and culture treatments as fixed factors. To test clipping effects on plant growth, repeated-measures ANOVA was performed, using environmental and culture treatments as fixed factors, plant height and aboveground biomass per plant using as dependent variables, separately, time of measurement (pre- or post-clipping) as a repeated factor. A significant two- or three-way interaction between clipping and environmental and/or culture treatment would indicate there was a shift or reversal in growth hierarch following clipping. Total biomass (i.e. pre- and post-clipping aboveground biomass plus belowground biomass) was analyzed in another two-way ANOVA, separately, using environmental and culture treatments as fixed factors. In cases where there was significant treatment effect(s), multiple comparisons were further examined using Turkey's HSD. Species were separately analyzed.

To determine competition intensity, random pair-wise comparisons were made between aboveground biomass (either pre- or postclipping) of individual plants grown in monoculture and mixtures in a given environmental treatment $\left(i^{\text {th }}\right)$. Competition intensity $\left(C_{\text {int }}\right)$ was calculated using relative neighbour effect (Markham \& Chanway 1996):

$$
C_{\text {int }}=\left(X P_{i}-X M_{i}\right) / x_{i}
$$

where $X P$ is the aboveground biomass per plant of a species grown in monoculture, and $X M$ is the total biomass per plant of the same species grown in mixture. $x$ is the greater value of $\left[X P_{i}, X M_{i}\right] . C_{\text {int }}$ values ranging between 0 and 1 indicate competition and values between -1 and 0 indicate facilitation.

A second repeated-measures ANOVA was performed, using environmental and culture treatments as fixed factors, ranked transformed $C_{\text {int }}$ as dependent variables (Conover \& Iman 1981), time of measurement (pre- or post-clipping) as a repeated factor. All data analyses were performed using SPSS 14.0. Unless otherwise noted, the 0.05 level of probability was used for significance tests.

\section{Results}

\section{Survival to clipping}

Clipping combined with $\mathrm{T}_{+} \mathrm{N}_{+} \mathrm{W}_{6.0}$ or $\mathrm{T}_{+} \mathrm{N}_{+} \mathrm{W}_{4.0}$ significantly reduced survival of $F$. rubra relative to clipping in $\mathrm{T}_{0} \mathrm{~N}_{0} \mathrm{~W}_{6.0}\left(F_{2,72}=33.215, P<0.001\right.$; Fig. 2$)$. Clipping combined with co-existing species (i.e. in mixtures) generally suppressed survival of $F$. rubra compared to clipping in monoculture $\left(F_{3,72}=4.212\right.$, $P=0.009)$. No significant interaction between environmental and culture treatments was detected. Compared to monoculture, interspecific competition reduced survival of $F$. rubra by $50 \sim 67 \%$ in $\mathrm{T}_{+} \mathrm{N}_{+} \mathrm{W}_{6.0}$ and by $61 \sim 83 \%$ in $\mathrm{T}_{+} \mathrm{N}_{+} \mathrm{W}_{4.0}$ (Fig. 2).

Clipping combined with $\mathrm{T}_{+} \mathrm{N}_{+} \mathrm{W}_{4.0}$ suppressed $T$. pratense survival $(-28 \%)$ profoundly $\left(F_{2,72}=14.108\right.$, $P<0.001$; Fig. 2 ), compared to $\mathrm{T}_{0} \mathrm{~N}_{0} \mathrm{~W}_{6.0}$ or $\mathrm{T}_{+} \mathrm{N}_{+}$ $\mathrm{W}_{6.0}$. The survival rate of $T$. pratense in MixFT was significantly $\left(F_{3,72}=3.816, P=0.014\right)$ facilitated $(+17 \%)$, compared to that in MonoT. No significant

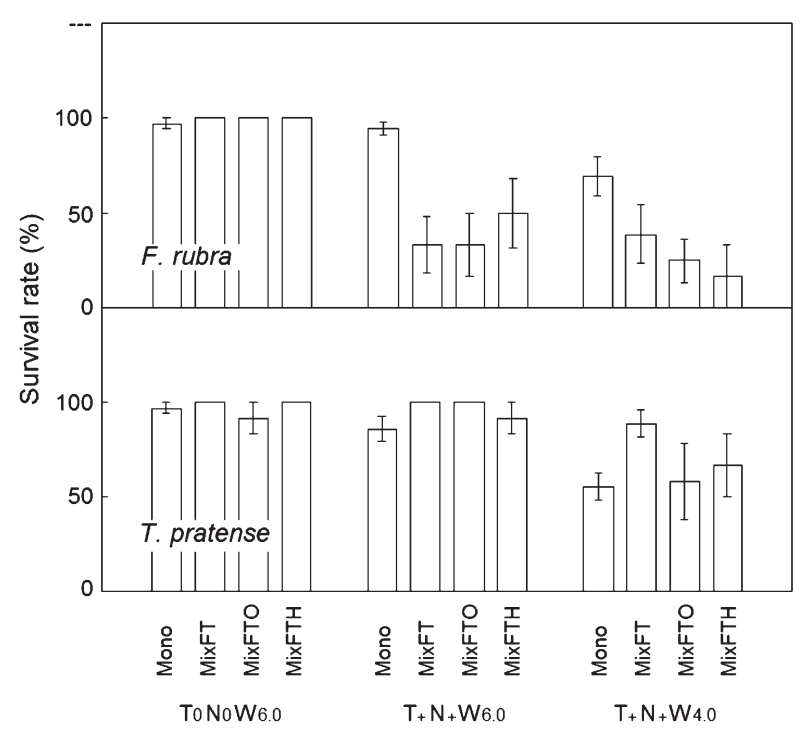

Fig. 2. Survival rate after clipping (mean values $\pm \mathrm{SE} ; n=6$ ) for Festuca rubra and Trifolium pratense under different treatments at the end of the experiment. Treatment codes are listed in "Abbreviations".

interaction between environmental treatment and culture treatment was detected.

\section{Primary and compensatory growth}

Repeated-measures ANOVA revealed that F. rubra grown in $\mathrm{T}_{0} \mathrm{~N}_{0} \mathrm{~W}_{6.0}$ was relativily taller than in $\mathrm{T}_{+} \mathrm{N}_{+} \mathrm{W}_{6.0}$ or $\mathrm{T}_{+} \mathrm{N}_{+} \mathrm{W}_{4.0}\left(F_{2,55}=71.916, P<0.001\right.$; Fig. 3). Co-exsiting species generally suppressed $F$. rubra height $\left(F_{3,55}=26.773, P<0.001\right)$, and the interspecific suppression was more profound in $\mathrm{T}_{+} \mathrm{N}_{+} \mathrm{W}_{6.0}$ and $\mathrm{T}_{+} \mathrm{N}_{+} \mathrm{W}_{4.0}\left(F_{6,55}=3.555, P=0.006\right)$, compared to $\mathrm{T}_{0} \mathrm{~N}_{0} \mathrm{~W}_{6.0}$. Clipping combined with $\mathrm{T}_{+} \mathrm{N}_{+} \mathrm{W}_{6.0}$ or $\mathrm{T}_{+} \mathrm{N}_{+} \mathrm{W}_{4.0}$ reduced regrowth height of $F$. rubra more profoundly than in $\mathrm{T}_{0} \mathrm{~N}_{0} \mathrm{~W}_{6.0}\left(F_{2,55}=5.544\right.$, $P=0.007)$. There was significant interaction of clipping $\times$ envromental treatment $\times$ culture treatment $\left(F_{6,55}=2.914, P=0.018\right)$, where the reduction was profound in mixtures growing in $\mathrm{T}_{+} \mathrm{N}_{+} \mathrm{W}_{6.0}$ or $\mathrm{T}_{+} \mathrm{N}_{+} \mathrm{W}_{4.0}$. However, no significant effects of coexisting species on regrowth height in F. rubra was detected.

Trifolium pratense growing in $\mathrm{T}_{+} \mathrm{N}_{+} \mathrm{W}_{6.0}$ was relatively taller than in $\mathrm{T}_{0} \mathrm{~N}_{0} \mathrm{~W}_{6.0}$ and $\mathrm{T}_{+} \mathrm{N}_{+} \mathrm{W}_{4.0}$ $\left(F_{2,69}=8.093, P=0.001\right.$; Fig. 3$)$. Height in $T$. pratense did not respond to culture treatment. No significant interaction between environmental and culture treatments was detected. Clipping combined with $\mathrm{T}_{+} \mathrm{N}_{+} \mathrm{W}_{4.0}$ or $\mathrm{T}_{+} \mathrm{N}_{+} \mathrm{W}_{6.0}$ significantly suppressed regrowth height in $T$. pratense than clipping with $\mathrm{T}_{0} \mathrm{~N}_{0} \mathrm{~W}_{6.0}\left(F_{2,69}=4.067, P=0.022\right.$; Fig. 3$)$. There was neither significant interaction of clipping $\times$ culture treatment nor clipping $\times$ environmental treatment $\times$ culture treatment on height of $T$. pratense.

Aboveground biomass in F. rubra was significantly higher in $\mathrm{T}_{0} \mathrm{~N}_{0} \mathrm{~W}_{6.0}$ than in $\mathrm{T}_{+} \mathrm{N}_{+} \mathrm{W}_{6.0}$ or $\mathrm{T}_{+} \mathrm{N}_{+} \mathrm{W}_{4.0}$ $\left(F_{2,55}=40.663, P<0.001\right.$; Fig. 4$)$. Co-existing species 


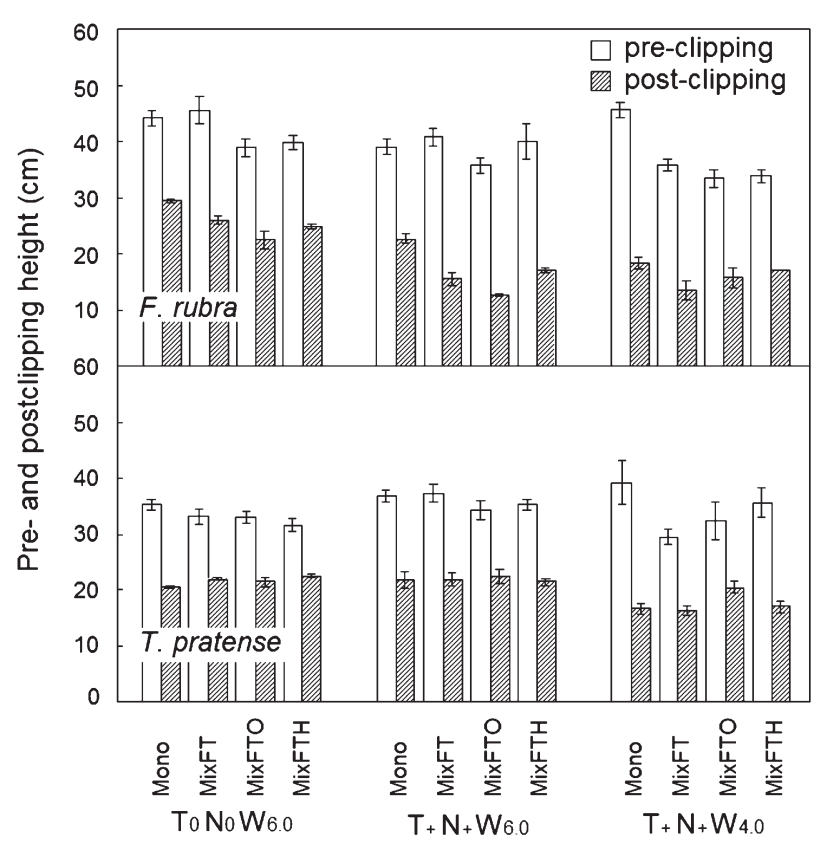

Fig. 3. Treatment effects on plant height (mean values $\pm \mathrm{SE}$; $n=6$ ) in Festuca rubra and Trifolium pratense. Treatment codes are listed in "Abbreviations".

significantly suppressed $F$. rubra on its aboveground biomass $\left(F_{3,55}=20.057, P<0.001\right)$. There was no significant interaction between environmental and culture treatments). Clipping effect on aboveground biomass in F. rubra was relatively severer in $\mathrm{T}_{+} \mathrm{N}_{+} \mathrm{W}_{6.0}$ compared to that in $\mathrm{T}_{0} \mathrm{~N}_{0} \mathrm{~W}_{6.0}$ and $\mathrm{T}_{+} \mathrm{N}_{+} \mathrm{W}_{4.0}\left(F_{1,55}=3.166\right.$, $P=0.050)$. However, there was neither significant interaction of clipping $\times$ culture treatment nor interaction of clipping $\times$ environmental treatment $\times$ culture treatment. Belowground biomass of F. rubra showed a decreased trend from $\mathrm{T}_{0} \mathrm{~N}_{0} \mathrm{~W}_{6.0}$ to $\mathrm{T}_{+} \mathrm{N}_{+} \mathrm{W}_{6.0}$ and further to $\mathrm{T}_{+} \mathrm{N}_{+} \mathrm{W}_{4.0}\left(F_{2,55}=29.031, P<0.001\right.$; Fig. 4$)$. Total biomass of $F$. rubra followed a similar response pattern with aboveground biomass $\left(F_{2,55}=42.861\right.$, $P<0.001$ for environmental treatment; $F_{3,55}=23.846$, $P<0.001$ for culture treatment; there was no significant interaction between environmental treatment $\times$ culture treatment (Fig. 4).

Aboveground biomass of $T$. pratense was significantly higher in $\mathrm{T}_{0} \mathrm{~N}_{0} \mathrm{~W}_{6.0}$ and $\mathrm{T}_{+} \mathrm{N}_{+} \mathrm{W}_{6.0}$ than in $\mathrm{T}_{+} \mathrm{N}_{+} \mathrm{W}_{4.0}\left(F_{2,69}=5.326, P=0.008\right.$; Fig. 4). Aboveground biomass of $T$. pratense was significantly higher in MixFTH than in MonoT $\left(F_{3,69}=3.339, P=0.025\right)$. There was no significant interaction between environmental treatment and culture treatment. Clipping effects on aboveground biomass in T. pratense did not vary among environmental treatments nor culture treatments. No significant interaction between environmental treatment and culture treatment was detected. Total biomass of $T$. pratense followed a similar response pattern with its aboveground biomass $\left(F_{2,69}=7.231\right.$, $P=0.002$ for environmental treatment; $F_{2,69}=3.048$, $P=0.036$ for culture treatment; and no significant interaction between enviromental $\times$ cutlure treatments (Fig. 4).

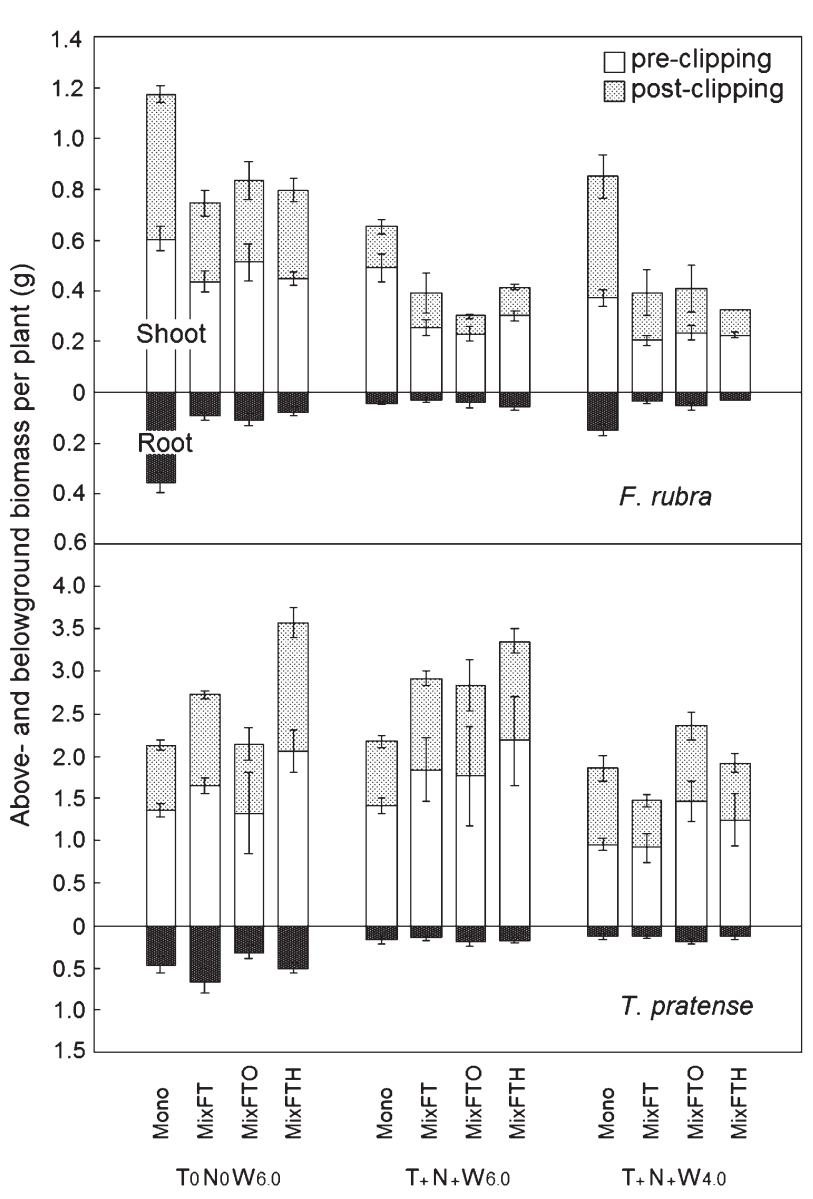

Fig. 4. Treatment effects on plant biomass (mean values $\pm \mathrm{SE}$; $n=6$ ) in Festuca rubra and Trifolium pratense. Treatment codes are listed in "Abbreviations".

\section{Competition variations}

Competition for F. rubra was less intensive in $\mathrm{T}_{0} \mathrm{~N}_{0}$ $\mathrm{W}_{6.0}$ and increased in $\mathrm{T}_{+} \mathrm{N}_{+} \mathrm{W}_{6.0}$ and $\mathrm{T}_{+} \mathrm{N}_{+} \mathrm{W}_{4.0}$ $\left(F_{2,36}=6.748, P=0.004\right.$; Fig. 5$)$. Competition for $F$. rubra did not significantly differ among culture treatments. There was no interaction between environmental treatment and culture treatment. Clipping significantly intensified competition for F. rubra $\left(F_{1,36}=5.105\right.$, $P=0.032)$ along either environmental treatments or culture treatments.

Competition intensity for $T$. pratense did not significantly respond to either environmental treatment or culture treatment. However, there was significnat interaction between environmental and culture treatments $\left(F_{1,51}=2.710, P=0.043\right.$; Fig. 5$)$. Clipping did not affect competition intensity for $T$. pratense in any environemntal treatment or culture treatment.

\section{Discussion}

\section{Species-specific response}

The two target species, F. rubra and T. pratense, responded differently to manipulated environmental and culture treatments. Altered environments $\left(\mathrm{T}_{+} \mathrm{N}_{+} \mathrm{W}_{6.0}\right.$ and $\mathrm{T}_{+} \mathrm{N}_{+} \mathrm{W}_{4.0}$ ) markedly suppressed $F$. rubra in its height, aboveground biomass, and survival following 


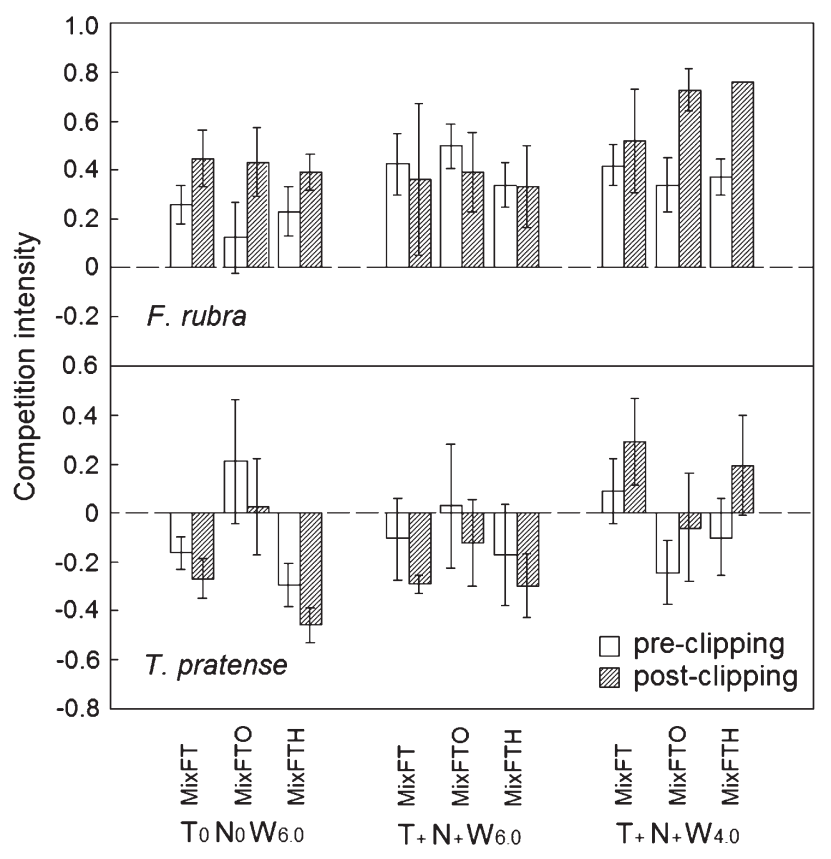

Fig. 5. Competition intensity (mean values $\pm \mathrm{SE} ; n=6$ ) for Festuca rubra and Trifolium pratense in relation to clipping under different treatments. Treatment codes are listed in "Abbreviations".

clipping when grown in mixtures. The greater the abiotic stress, the more significant the neighbour effects for F. rubra. On the contrary, T. pratense remained a similar growth responses across experimental conditions (i.e. environmental and culture treatments).

Plant compensatory growth following clipping was species-dependent and environment-dependent. For example, clipped F. rubra plants exhibited a compensation growth of $\sim 80 \%$ of pre-clipping aboveground biomass in $\mathrm{T}_{0} \mathrm{~N}_{0} \mathrm{~W}_{6.0}$ and $\mathrm{T}_{+} \mathrm{N}_{+} \mathrm{W}_{4.0}$, and only of $\sim 39 \%$ in $\mathrm{T}_{+} \mathrm{N}_{+} \mathrm{W}_{6.0}$. However, compensatory growth in T. pratense did not markedly differ among three environmental treatments. This result may be explained by species differences in optimal growth environments and tolerance to a particular abiotic stress (Hartley \& Mitchell 2005). Co-existing species with different physiological and ecological properties may modify and amplify a particular plant's environmental response (Dunnett \& Grime 1999). On the other hand, canopy removal through defoliation or clipping will alter the availability of resource, leading to changed interaction between plant and environment (McNaughton 1992). For example, Magda et al. (2006) observed that grazing created a dense grass sward structure which leads to a high level of light competition. Therefore, a fast-growing species, e.g. T. pratense, is advantageous for new growth following defoliation. Moreover, defoliation may alter competition balance between co-existing species (Louda et al. 1990), leading to different responses in survival and growth to defoliation (van Der Wal et al. 2000; Magda et al. 2006).

Both total biomass per plant (i.e. F. rubra and T. pratense) and total pot biomass were significantly different among three environmental treatments, with the lowest in $\mathrm{T}_{+} \mathrm{N}_{+} \mathrm{W}_{4.0}$, we may say the productivities significantly differed among the three environments. We observed that both species showed a much stronger compensatory growth, in terms of aboveground biomass, in $\mathrm{T}_{+} \mathrm{N}_{+} \mathrm{W}_{4.0}$ than in $\mathrm{T}_{0} \mathrm{~N}_{0} \mathrm{~W}_{6.0}$ or $\mathrm{T}_{+} \mathrm{N}_{+} \mathrm{W}_{6.0}$ (c. $85 \%$ for F. rubra and c. $68 \%$ for $T$. pratense). This finding is supported by the conceptual model developed by Hilbert et al. (1981). Their model predicts that plants in stress environment with growth rate far below their maximum penitential are more likely to respond positively to clipping than plants growing in optimal conditions. Experimental studies (review in Ferraro \& Oesterheld 2002) also reported that plants growing at low nutrient or water availability exhibited stronger compensatory growth than those under more favorable conditions.

\section{Clipping effects on competition}

As $T$. pratense retained the same competitive superiority following clipping, competition intensity for $F$. rubra, measured on aboveground biomass, generally increased after clipping. These different competitive responses to clipping may be mainly resulted from an unbalanced loss of aboveground tissue and reserves through clipping, since the aboveground biomass of $T$. pratense was two- to three-time higher than the aboveground biomass of F. rubra before clipping. Compared to $F$. rubra, the fast-growing species $T$. pratense may more rely on carbohydrate reserves stored in roots for regrowth due to loss of foliage. On other words, a dramatic decrease in carbohydrate reserves in T. pratense may lead to an insufficient carbon supply to support a fast regrowth following a severe defoliation (Coley et al. 1985). However, the N-fixation ability of T. pratense will have a greater capacity for regrowth and competition when new leaves occurred. Carlsson \& HussDanell (2003) found that the N-fixation ability of $T$. pratense allows legume to survive and compete with grass through a critical period when legume roots and grass roots must compete for soil nutrients. In high soil fertility, grasses and legumes compete predominantly for light (Schwinning \& Parsons 1996). The broad-, flat-leaved T. pratense would be advantageous in intercepting incoming light, compared with narrow-leaved F. rubra (Fynn et al. 2005). Consequently, the former will shade out the latter or competing neighbours. However, as asymmetry competition may occur when there are pronounced variations in plant size within a community (Goldberg \& Werner 1983). Otherwise, the regulatory mechanisms of species coexistence may be due to some parameters other than shoot size, such as speciesspecific competitive ability, or growth form of the neighbouring species (Hara 1993).

In conclusion, F. rubra and T. pratense responded differently in compensatory growth to environmental change and co-existing species. Interspecies competition was modified and amplified in the complex interaction between clipping and environmental change. Speciesdependent responses are associated with the differences 
in their physiological and ecological traits. The present study emphasizes that predicting the plant assemblage response in the face of global change requires in understanding the integrating effects of abiotic and biotic factors.

\section{Acknowledgements}

We thank Tang Min, Yang Jian, Werner Läuchli, Wang Zuyuan, Anna Brechbül, Susanne Griebel, and Peter Schweizer for technical assistance. We thank Ivano Brunner and Daniel Rigling for allowing us to use the glasshouse. We specially thank Dr. Edward G. Reekie for his constructive suggestions on earlier versions of this manuscript.

\section{References}

Augustine D.J. \& MacNaughton S.J. 1998. Ungulate effects on the functional species composition of plant communities: herbivore selectivity and plant tolerance. J. Wildlife Manag. 62: $1165-1183$.

Belsky A.J. 1986. Does herbivory benefit plants? $\underline{\text { A review of the }}$ evidence. Am. Nat. 127: 870-892.

Bullock J.M., Franklin J., Stevenson M.J., Silvertown J., Coulson S.J., Gregory S.J. \& Tofts R. 2001. A plant trait analysis of responses to grazing in a long-term experiment. J. Appl. Ecol. 38: 253-267.

Carlsson G. \& Huss-Danell K. 2003. Nitrogen fixation in perennial forage legumes in the field. Plant Soil 253: 353-372.

Chapin F.S.III \& McNaughton S.J. 1989. Lack of compensatory growth under phosphorus deficiency in grazing-adapted grasses from the Serengeti Plains. Oecologia 79: 551-557.

Coley P.D., Bryant J.P. \& Chapin F.S.III. 1985. Resource availability and plant antiherbivore defense. Science 230: 895-899.

Conover W.J. \& Iman R.L. 1981. Rank transformations as a bridge between parametric and nonparamentric statistics. Am. Stat. 35: 124-133.

Crawley M.J. 1997. Plant Ecology 2nd edn. Blackwell Science, Oxford.

Dunnett N.P. \& Grime J.P. 1999. Competition as an amplifier of short-term vegetation responses to climate: an experimental test. Funct. Ecol. 13: 388-395.

Ferraro D.O. \& Oesterheld M. 2002. Effect of defoliation on grass growth: a quantitative review. Oikos 98: 125-133.

Fynn R.W.S., Morris C.D. \& Kirkman K.P. 2005. Plant strategies and trait trade-offs influence trends in competitive ability along gradients of soil fertility and disturbance. J. Ecol. 93: 384-394.

Gonzalez B., Boucaud J., Salette J., Langlois J. \& Duyme M. 1989. Changes in stubble carbohydrate content during regrowth of defoliated perennial ryegrass (Lolium perenne L.) on two nitrogen levels. Grass Forage Sci. 44: 411-415.

Goldberg D.E. \& Werner P.A. 1983. Equivalence of competitors in plant communities: a null hypothesis and a field experimental approach. Am. J. Bot. 70: 1098-1104.

Hara T. 1993. Effects of variation in individual growth on plant species coexistence. J. Veg. Sci. 4: 409-416.

Hartley S.E. \& Amos L. 1999. Competitive interactions between Nardus stricta L. and Calluna vulgaris (L.) Hull: the effect of fertilizer and defoliation on above- and belowground performance. J. Ecol. 87: 330-340.

Hartley S.E. \& Mitchell R.J. 2005. Manipulation of nutrients and grazing levels on heather moorland: changes in Calluna dominance and consequences for community composition. J. Ecol. 93: $990-1004$.

Hilbert D.W., Swift D.M., Detling J.K. \& Dyer M.I. 1981. Relative growth rates and the grazing optimization hypothesis. Oecologia 51: 14-18.
Houdijk A.L.F.M., Verbeek P.J.M., van Dijk H.F.G. \& Roelofs J.G.M. 1993. Distribution and decline of endangered herbaceous heathland species in relation to the chemical composition of the soil. Plant Soil. 148: 137-143.

IPCC 2007: Summary for policymakers, pp. 2-18. In: Solomon S., Qin D., Manning M., Chen Z., Marquis M., Averyt K.B., Tignor M. \& Miller H.L. (eds), Climate Change 2007: The Physical Science Basis. Contribution of Working Group I to the Fourth Assessment Report of the Intergovernmental Panel on Climate Change. Cambridge University Press, Cambridge, United Kingdom and New York, NY, USA.

Jarvis S.C. \& Macduff J.H. 1989. Nitrate nutrition of grasses from steady-state supplies in flowing solution culture following nitrate deprivation and/or defoliation. I. Recovery of uptake and growth and their interactions. J. Exp. Bot. 40: 965-975.

Lee T.D. \& Bazzaz F.A. 1980. Effects of defoliation and competition on growth and reproduction in the annual plant $\underline{\text { Abutilon }}$ theophrasti. J. Ecol. 68: 813-821.

Lestienne F., Thornton B. \& Gastal F. 2006. Impact of defoliation intensity and frequency on $N$ uptake and mobilization in Lolium perenne. J. Exp. Bot. 57: 997-1006.

Li M.H., Kräuchi N. \& Gao S.P. 2006. Global warming: can existing reserves really preserve current levels of biological diversity? J. Integr. Plant Biol. 48: 255-259.

Louda S.M., Keeler K.H. \& Holt R.D. 1990. Herbivore influences on plant performance and competitive interactions, pp. 414444. In: Grace J.B. \& Tilman D. (eds), Perspectives on Plant Competition. Academic Press, San Diego.

Magda D., Duru M., Huguenin J. \& Gleizes B. 2006. Impact of shading and cutting on the demography and composition of Mimosa pudica L., a ligneous weed species of tropical grasslands. Grass Forage Sci. 61: 89-96.

Markham J.H. \& Chanway C.P. 1996. Measuring plant neighbour effects. Funct. Ecol. 10: 548-549.

McNaughton S.J. 1983. Compensatory plant growth as a response to herbivory. Oikos 40: 329-336.

McNaughton S.J. 1992. Laboratory-simulated grazing: interactive effects of defoliation and canopy closure on Serengeti grasses. Ecology 73: 170-182.

Morvan-Bertrand A., Pavis N., Boucaud J. \& Prud'homme M.P. 1999. Partitioning of reserve and newly assimilated carbon in roots and leaf tissues of Lolium perenne during regrowth after defoliation: assessment by ${ }^{13} \mathrm{C}$ steady-state labelling and carbohydrate analysis. Plant Cell Environ. 22: 1097-1108.

Painter E.L. \& Detling J.K. 1981. Effects of defoliation on net photosynthesis and regrowth of western wheatgrass. J. Range Manage. 34: 68-71.

Parsons A.J., Leafe E.L., Collett B. \& Stiles W. 1983. The physiology of grass production under grazing. I. Characteristics of leaf and canopy photosynthesis of continuously-grazed swards. J. Appl. Ecol. 20: 117-126.

Roem W.J. \& Berendse F. 2000. Soil acidity and nutrient supply ratio as possible factors determining changes in plant species diversity in grassland and heathland communities. Biol. Conserv. 92: 151-161.

Sala O.E., Chapin F.S.III, Armesto J.J., Berlow R., Bloomfield J., Dirzo R., Huber-Sanwald E., Huenneke L.F., Jackson R.B., Kinzig A., Leemans R., Lodge D., Mooney H.A., Oesterheld M., Poff N.L., Sykes M.T., Walker B.H., Walker M. \& Wall D.H. 2000. Global biodiversity scenarios for the year 2100 . Science 287: 1770-1774.

Schwinning S. \& Parsons A.J. 1996. Analysis of the coexistence mechanisms for grasses and legumes in grazing systems. J. Ecol. 84: 799-813.

Shaw M.R., Zavaleta E.S., Chiariello N.R., Cleland E.E., Mooney H.A. \& Field C.B. 2002. Grassland responses to global environmental changes suppressed by elevated $\mathrm{CO}_{2}$. Science 298: 1987-1990.

van Der Wal R., Egas M., van Der Veen A. \& Bakker J. 2000. Effects of resource competition and herbivory on plant performance along a natural productivity gradient. J. Ecol. 88: 317-330.

van Staalduinen M.A. \& Anten N.P.R. 2005. Differences in the compensatory growth of two co-occurring grass species in relation to water availability. Oecologia 146: 190-199. 
Vitousek P.M., Aber J.D., Howarth R.W., Likens G.E., Matson P.A., Schindler D.W., Schlesinger W.H. \& Tilman D.G. 1997. Human alteration of the global nitrogen cycle: sources and consequences. Ecol. Appl. 7: 737-750.
Zavaleta E.S., Shaw M.R., Chiariello N.R., Mooney H.A. \& Field C.B. 2003. Additive effects of simulated climate changes, elevated $\mathrm{CO}_{2}$, and nitrogen deposition on grassland diversity. P. Natl. Acad. Sci. USA 100: 7650-7654.

Received November 28, 2007 Accepted September 8, 2008 